\title{
Genome-wide characterization and expression profiling of the Phospholipase $C$ (PLC) gene family in three orchids of economic importance
}

\author{
Madhvi Kanchan ${ }^{1 \dagger}$, Thakku R. Ramkumar $^{2 \dagger}$, Himani $^{1}$ and Jaspreet K. Sembi ${ }^{1 *}$ (B)
}

\begin{abstract}
Background: Phospholipases hydrolyze glycerophospholipids and generate diverse lipid-derived molecules with secondary messenger activity. Out of these, phospholipase C (PLC) specifically cleaves the phospholipids at ester linkages and yields diacylglycerol (DAG) and phosphorylated head groups. PLCs are classified further as phosphatidylinositol-specific PLCS (PI-PLCs) and non-specific PLCs with biased specificity for phosphatidylcholine (NPC/PC-PLC).

Results: In the present report, we identified and characterized PLC genes in the genomes of three orchids, Phalaenopsis equestris (seven PePLCS), Dendrobium catenatum (eight DCPLCS), and Apostasia shenzhenica (seven AsPLCS). Multiple sequence alignment analysis confirmed the presence of conserved $X$ and $Y$ catalytic domains, calcium/lipid-binding domain (C2 domain) at the $\mathrm{C}$ terminal region, and EF-hand at the N-terminal region in PI-PLC proteins and esterase domain in PC-PLC. Systematic phylogenetic analysis established the relationship of the PLC protein sequences and clustered them into two groups (PI-PLC and PC-PLC) along with those of Arabidopsis thaliana and Oryza sativa. Gene architecture studies showed the presence of nine exons in all PI-PLC genes while the number varied from one to five in PC-PLCS. RNA-seq-based spatio-temporal expression profile for $P L C$ genes was generated, which showed that PePC-PLC1, PePC-PLC2A, DCPC-PLC1A, DCPC-PLC1B, DCPC-PLC2, DCPC-PLC1B, and AsPC$P L C 1$ had significant expression in all reproductive and vegetative tissues. The expression profile is matched to their upstream cis-regulatory promoter elements, which indicates that PLC genes have a role in various growth and development processes and during stress responses.
\end{abstract}

Conclusions: The present study unwrapped the opportunity for functional characterization of selected $P L C$ genes in planta for plant improvement.

Keywords: Orchids, Phospholipase, Phalaenopsis equestris, Dendrobium catenatum, Apostasia shenzhenica

\section{Background}

The plasma membrane acts as a barrier between cells and the outside environment and plays a major role in the development and protection of plants from external stresses. Phospholipids act as building blocks of the

\footnotetext{
* Correspondence: jaspreet.sembi@pu.ac.in

${ }^{\dagger}$ Madhvi Kanchan and Thakku R. Ramkumar contributed equally to this work. 'Department of Botany, Panjab University, Chandigarh 160014, India Full list of author information is available at the end of the article
}

plasma membrane; the composition of these compounds dynamically change, during various growth and developmental processes and in response to abiotic and biotic stresses [1]. These compositional changes are essential for the maintenance of membrane integrity and stability, which is necessary for the overall health and growth of plants. The phospholipase superfamily is a large family of enzymes, which is involved in the above process. Phospholipases are considered a diverse group of 
principle enzymes involved in lipid hydrolysis [2]. Essentially, all the lipid derivatives are supposed to play a major role as signaling compounds in various cellular processes. The phospholipase superfamily on the basis of their substrate specificity is categorized into three sub-families, phospholipase A (PLA), phospholipase C (PLC), and phospholipase D (PLD). Phospholipase C is considered one of the essential lipid-hydrolyzing enzymes; it cleaves the ester linkage of phospholipid molecule of the plasma membrane and yields a watersoluble phospholipid head group and diacylglycerol (DAG) [3]. The phospholipase C sub-family is further classified on the basis of the affinity toward the phospholipid head group as the substrate, into two categories, phosphatidylinositol-specific phospholipase C (PI-PLC) and non-specific phospholipase with biased specificity for phosphatidylcholine (PC-PLC/NPC). PCPLC mainly hydrolyze the membrane lipids (phosphatidylcholine and phosphatidylethanolamine) and acts in a calcium-independent manner [4-8]. In addition to this, it is reported that in plant cells phosphorylated products of DAG, the phosphatidic acid (PA), diacylglycerol pyrophosphate (DGPP), and hexakisphosphate (IP6) acts as secondary messengers [9]. The $P L C$ gene family was first reported in Arabidopsis thaliana, where nine PI-PLC and six $P C-P L C$ genes were identified $[10,11]$. After Arabidopsis, PLC genes have been identified from a number of plant species such as Oryza sativa [12], Triticum turgidum [13], Gossypium hirsutum, G. arboretum, and G. raimondii [9], Lycopersicon esculentum [14], Glycine max [5, 15], Solanum tuberosum [16], Pisum sativum [17], Brassica napus [18, 19], Vigna radiata L. [20], Avena sativa [21], Lilium daviddi [22], Zea mays [23], and Physcomitrella patens [24, 25]. Members of both sub-groups of PLC have their own specific signature domains: PI-PLC group consists of X and Y catalytic domains, which leads to the formation of the TIM (triphosphate isomerase) barrel-like structure essential for the phosphoesterase activity, a calcium/lipid-binding domain ( $\mathrm{C} 2$ domain) at the $\mathrm{C}$ terminal region, and $\mathrm{EF}-$ hand at $\mathrm{N}$-terminal region to guide the binding of the enzyme to a membrane and PC-PLC contains only esterase domain.

PI-PLC genes regulate various cellular processes including signal transduction, cytoskeleton dynamic, vesicular trafficking, and remodeling of the cell by means of various lipid intermediates, the phosphatidic acid, diacylglycerol, inositol 1,4, 5-trisphosphate (IP3), and inositol hexakisphosphate (IP6) $[11,12,26]$. The members of the PI-PLC subgroups are activated by various stress conditions such as cold, salt, and drought stress [27-29]. The activation of PI-PLC during stress conditions has been reported in various plants such as Zea mays, where ZmPLC1 gets upregulated and enhances grain production during dehydration and cold stress [23]. Similarly, BnPLC2 of Brassica napus shows high expression in response to drought stress [18]. Genome-wide analysis of the PLC gene family in $B$. napus suggested that the overexpression of BnaPI-PLC1 and BnaPI-PLC2 as well as BnaNPC1 genes enhances the DAG level under drought stress [19]. Knockout studies of Arabidopsis thaliana, AtPLC3, and AtPLC9 result in enhanced sensitivity to heat revealing their role in thermotolerance [11, 30, 31]. Additionally, PI-PLCs of tomato were found to be involved in hypersensitive response (HR) and immunity exposure [14, 26]. The role in plant immunity is also established in Arabidopsis thaliana [32]. The PI$P L C$ is also found to play important role in gravitropism, plant hormonal responses, photosynthesis and flowering $[18,24]$. In Pyrus, PI-PLC is involved in the maintenance of the self-incompatibility [33]. The PC-PLC (NPC) are responsible for lipid conversion during phosphatelimiting conditions [29]. These play essential role in number of physiological processes and various biotic and abiotic stress responses [34, 35]. In addition to this, it is found in rice that $P C-P L C / N P C$ also affect the root architecture by brassinolide response [12].

During post-genomics era, the whole genome sequencing of Phalaenopsis equestris [36], Dendrobium catenatum [37] and Apostasia shenzhenica [38] plants leads to ample opportunities for genome-wide characterization of various gene families in these orchids. However, such studies are rare in case of orchids. P. equestris is a prized commercial plant due to its floral morphology. D. catenatum also has floricultural importance but it is mainly known for its antioxidant, immune modulation and vasodilation properties as reported in traditional Chinese medicines [39]. A. shenzhenica, a primitive terrestrial orchid, has evolutionary significance due to the presence of contrasting features to the general morphology of orchids, e.g., actinomorphic flowers, indistinct labellum, absence of pollinia, and resupination of ovary and rudimentary gynostemium, supporting its divergence from Orchidaceae [40]. Orchids, in general, are important plants for their floricultural and medicinal value. They are endangered of survival due to various environmental stresses and excessive exploitation for human use. The role of the PLC gene family in growth and development as well as in stress tolerance is well established. Several PLC members have been reported to be involved in various cellular processes and signaling networks, which are triggered by stressful environmental cues. This makes the PLC genes potential candidates for genetic engineering for the production of plants with enhanced growth and stress tolerance.

The present study on identification and characterization of the PLC gene family in orchids is proposed to provide a better understanding of the 
structure, function, and phylogenetic relationships of $P L C$ genes which in turn can facilitate their functional characterization and utilization for the introduction of improved traits leading to better growth and stress tolerance in these immensely important plants.

\section{Methods}

Identification of PLC gene family proteins and analysis of primary structure

Phospholipase $\mathrm{C}$ protein sequences of Arabidopsis thaliana (AtPLC) and Oryza sativa (OsPLC) were used as query sequences and Blastp was carried out against the NCBI derived $P$. equestris [36], D. catenatum [37], and A. shenzhenica [38] protein database (https://www.ncbi. nlm.nih.gov/protein) [41]. The retrieved PePLC, DcPLC, and AsPLC sequences were then analyzed for the presence of $\mathrm{X}$ and $\mathrm{Y}$ catalytic domains, calcium/lipid-binding domain, and esterase domain with SMART server (http://smart.embl-heidelberg.de/ )[42]. The domain architecture was constructed using Expasy - Prosite (https://prosite.expasy.org/ )[43]. The conserved catalytic centers were located with the help of multiple sequence alignment using the MULTALIN tool (http://multalin. toulouse.inra.fr/multalin/ )[44]. The MEME suite server (http://meme-suite.org/tools/meme )[45], with preset parameters (maximum number of motifs -05 , number of repetitions - any, optimum motif width $-\geq 6$ and $\leq$ 200) was used for the identification of conserved motifs.

\section{Determination of physical parameters}

The physiochemical characterization of PLC protein sequences (molecular weight, aliphatic index, instability index, isoelectric point, and hydropathicity) were done using the Expasy-ProtParam server (https:// web.expasy. org/protparam) [46]. The sub-cellular localization of protein was predicted by CELLO v.2.5 (http://cello.life. nctu. edu.tw/) [47] and WoLF PSORT (https://www. genscript. com/wolf-psort.html )[48]. The signal peptide and transmembrane regions were detected using online server SignalP.4.0 (http://www.cbs.dtu.dk/services/ signalp/ )[49] and TMHMM v.2.0 (http://www.cbs.dtu. $\mathrm{dk} /$ services/TMHMM/) [50].

\section{Phylogenetic analysis and ortholog prediction}

The full-length PLC protein sequences (AtPLC, OsPLC, PePLC, DcPLC, and AsPLC ) were aligned with the MUSCLE program and the phylogenetic tree was then constructed using MEGA X tool (http://www. megasoftware.net/) [51] by the maximum-likelihood method at a bootstrap value of 1000 and the model selected was the Jones-Taylor-Thornton (JTT) model.

The orthologs for PePLC, DcPLC, and AsPLC protein sequences were predicted using local NCBI BLASTp search, each candidate PLC protein sequence querying independently against each other, and the best bidirectional blast hit with an $e$ value less than $10^{-5}$ was selected [52]. Orthologs were also detected using OrthoVenn2 ( https://orthovenn2.bioinfotoolkits.net ) [53]

\section{Gene structure and promoter analysis}

The coding sequences (CDS), gene sequences, and promoter sequences were retrieved for each PLC protein from the NCBI database. CDS sequences and gene sequences were analyzed by using Gene Structure Display Server 2.0 (http://gsds.cbi.pku.edu.cn/ )[54] for the exonintron architecture. The cis-regulatory elements of the PLC protein sequences were recognized in $1.5-\mathrm{kb}$ upstream sequences using PLACE server (https://sogo.dna. affrc.go.jp/cgi-bin/sogo.cgi?lang=en\&pj=640\&action $=$ page\&page $=$ newplace ) [55]. Further analysis of promoter elements was carried out for the identification of common specific promoters using the Venn diagram tool GeneVenn (http://GeneVenn (sourceforge.net)/) [56].

\section{Duplication events prediction}

The duplication events among PePLC, DcPLC, and AsPLC CDS sequences were predicted with the help of sequence similarity index obtained from the MUSCLE tool (https://www.ebi.ac.uk/Tools/msa/muscle/) [57]. The genes sharing $\geq 80 \%$ identity were considered duplicates [58].

\section{Expression analysis}

The CDS sequences of $P L C$ genes were used for the BLASTn search against the high-throughput RNAseq data available at the SRA database (https://www. ncbi.nlm.nih.gov/sra) [59] for different tissues in $P$. equestris [leaf (SRX1074879), root (SRX1074875), stem (SRX1074876), flower bud (SRX1074880), sepal (SRX1806366), petal (SRX1806365), labellum (SRX1806348), pollinia (SRX2938663), and gynostemium (SRX1805894)]; D. catenatum [leaf (SRX2251517), root (SRX2938667), green root tip (SRX2251515), white part of root (SRX2251514), stem (SRX2251516), flower bud (SRX2251519), sepal (SRX2251513), lip (SRX2251518), pollinia (SRX2938662), and gynostemium (SRX2251512)]; and A. shenzhenica [tuber (SRX2938654), seed (SRX2938653), and pollen (SRX2938652)] [37, 38]. The total hits were counted and RPKM values (reads per kilobase per million) were calculated using the formula RPKM $=\left(C \times 10^{9}\right) /(N \times L)$, where $C=$ number of reads mapped to the sequence, $N=$ total mapped reads in the experiment, and $L=$ exon length in base-pairs for the gene. Heat maps for the spatio-temporal expression of PePLC, $D c P L C$, and $A s P L C$ genes were generated using Hierarchical Clustering Explorer 3.5 (http://www.cs.umd.edu/hcil/ hce/) $[60,61]$. 
Molecular modeling

Secondary structures

To predict secondary structures (alpha helices, random coils, beta turns, and extended strands) of PLC protein sequences, the SOPMA secondary structure prediction tool was used (https://npsa-prabi.ibcp.fr/cgi-bin/npsa_ automat.pl?page=/NPSA/npsa_sopma.html )[62].

\section{D structure prediction}

The three-dimensional structure of PLC protein sequences was predicted using homology modeling in the online Phyre2 server (http://www.sbg.bio.ic.ac.uk/ phyre2/index.cgi) [63] and PyMOL (https://pymol.org/)
[64] was used for the visualization of the protein $3 \mathrm{D}$ structure.

\section{Results}

Identification, ortholog prediction and domain analysis Upon thorough exploration of $P$. equestris, D. catenatum, and A. shenzhenica genome, a total of seven, eight, and seven PLC sequences were predicted respectively. The PLC gene family in all three plants could be successfully divided into two major groups, phosphatidylinositol-specific PLC (PI-PLCs) and nonspecific phospholipase $\mathrm{C}$ with specific catalytic activity for phosphatidylcholine (PC-PLC/NPC). The PLC gene

Table 1 Ortholog prediction for PePLC, DcPLC, and AsPLC

\begin{tabular}{|l|l|c|l|l|l|l|}
\hline \multicolumn{5}{|c|}{ NCBI Protein blast } & \multicolumn{3}{|c|}{ OrthoVenn } \\
\hline Protein Name & Orthologs & $\boldsymbol{E}$ value & Identity & Protein Name & Orthologs & $\boldsymbol{E}$ value \\
\hline PePI-PLC6A & DcPI-PLC6A & 0 & $89.43 \%$ & PePI-PLC6A & DcPI-PLC6A & 1.14373 \\
\hline PePI-PLC6C & DcPI-PLC6B & 0 & $84.62 \%$ & PePI-PLC6C & DcPI-PLC6B & 1.15268 \\
\hline PePI-PLC6B & DcPI-PLC6A & 0 & $79.19 \%$ & PePI-PLC6B & - & - \\
\hline PePC-PLC1 & DcPC-PLC1A & 0 & $90.33 \%$ & PePC-PLC1 & DcPC-PLC1A & 1.11993 \\
\hline PePC-PLC2B & DcPC-PLC2 & 0 & $79.50 \%$ & PePC-PLC2B & - & - \\
\hline PePC-PLC2A & DcPC-PLC2 & 0 & $87.60 \%$ & PePC-PLC2A & DcPC-PLC2 & 1.00243 \\
\hline PePC-PLC4 & DcPC-PLC4 & 0 & $77.39 \%$ & PePC-PLC4 & DcPC-PLC4 & 1.02528 \\
\hline PePI-PLC6A & AsPI-PLC6 & 0 & $79.00 \%$ & PePI-PLC6A & AsPI-PLC6 & 1.21632 \\
\hline PePI-PLC6C & AsPI-PLC6 & 0 & $68.57 \%$ & PePI-PLC6C & - & - \\
\hline PePI-PLC6B & AsPI-PLC6 & 0 & $75.34 \%$ & PePI-PLC6B & - & - \\
\hline PePC-PLC1 & AsPC-PLC1 & 0 & $88.32 \%$ & PePC-PLC1 & AsPC-PLC1 & 1.24949 \\
\hline PePC-PLC2B & AsPC-PLC2 & 0 & $81.23 \%$ & PePC-PLC2B & AsPC-PLC2 & 1.10524 \\
\hline PePC-PLC2A & AsPC-PLC2 & 0 & $80.95 \%$ & PePC-PLC2A & - & - \\
\hline PePC-PLC4 & AsPC-PLC4 & 0 & $77.31 \%$ & PePC-PLC4 & AsPC-PLC4 & 1.06051 \\
\hline DcPI-PLC6A & AsPI-PLC6 & 0 & $81.51 \%$ & DcPI-PLC6A & AsPI-PLC6 & 1.14646 \\
\hline DcPI-PLC6B & AsPI-PLC6 & 0 & $69.78 \%$ & DcPI-PLC6B & - & - \\
\hline DcPI-PLC8A & AsPI-PLC6 & 0.003 & $31.58 \%$ & DcPI-PLC8A & - & \\
\hline DcPC-PLC1A & AsPC-PLC1 & 0 & $89.67 \%$ & DcPC-PLC1A & AsPC-PLC1 & 1.19257 \\
\hline DcPC-PLC2 & AsPC-PLC2 & 0 & $83.37 \%$ & DcPC-PLC2 & AsPC-PLC2 & 1.06384 \\
\hline DcPC-PLC1B & AsPC-PLC1 & 0 & $89.36 \%$ & DcPC-PLC1B & - & - \\
\hline DcPC-PLC5 & AsPC-PLC5 & 0 & $73.84 \%$ & DcPC-PLC5 & AsPC-PLC5 & 0.80452 \\
\hline DcPC-PLC4 & AsPC-PLC4 & 0 & $67.70 \%$ & DcPC-PLC4 & AsPC-PLC4 & 0.9532 \\
\hline
\end{tabular}

\begin{tabular}{|l|l|}
\hline & Phalaenopsis equestris \\
\hline & Dendrobium catenatum \\
\hline & Apostasia shenzhenica \\
\hline
\end{tabular}


family is represented by three PI-PLC and four PC-PLC genes in $P$. equestris, three $P I-P L C$ and five $P C-P L C$ in $D$. catenatum, and two PI-PLC and five PC-PLC in A. shenzhenica. Additionally, orthologous genes for PePLC, $D c P L C$, and $A s P L C$ were predicted (Table 1). The nomenclature of proteins and their respective genes was done in accordance with their closest phylogenetic homologs in A. thaliana and O. sativa $[10,12]$. Furthermore, structure analysis indicated that all the members of the PePI-PLC, DcPI-PLC, and AsPI-PLC groups comprised of $\mathrm{X}$ and $\mathrm{Y}$ catalytic domains and the calcium/ lipid-binding domain. PC-PLC members were characterized by the presence of the phosphoesterase domain only (Fig. 1). Additionally, multiple sequence alignment showed the presence of a conserved region of EF-hand, $\mathrm{X}$-box, Y-Box, and C-terminus $\mathrm{C} 2$ domain region in all PI-PLC sequences, whereas PC-PLC proteins were observed to have ENRSFDxxxG, TxPNR, DExxGxxDHV, GxRVPxxxxxP, and variable C-terminus region (Fig. 2). Motif analysis showed that all PLC protein sequences under study have the five highly conserved motifs. The conserved motifs are identified separately for both subgroups of the PLC family (Fig. 3).

In $P$. equestris, three protein sequences were identified along with isoforms with the help of the NCBI database search for protein gene ID. Every two proteins or a group of proteins sharing the same gene ID was considered an isoform. The PePI-PLC6C (XP 020579604.1; Gene ID: 110024153) was predicted to have two isoforms (XP_020579605.1 and XP_ 020579606.1), PePI-PLC6B (XP_020578229.1; Gene ID: 110023257) have one isoform (XP_020578230.1) and PePC-PLC2B (XP_020583114.1; Gene ID: 110026499) also have one isoform (XP_020583115.1); we have considered the longest isoform for further analysis, whereas no isoforms were identified for any DcPLC and AsPLC proteins.

\section{Protein characterization}

Physico-chemical characterization of all PLC protein sequences was comparable in all three plants (Table 2). The average and range values for each physico-chemical property were calculated separately for both sub-groups: PI-PLC and PC-PLC. The peptide length for PePI-PLC ranged from 590 amino acid (aa) to 597aa, DcPI-PLC ranged from 594aa to 604aa and AsPI-PLC ranged from 588 aa to 595aa with an average of 594aa, 599aa and 591aa, respectively. The DcPI-PLC8A has the smallest peptide length, which indicates its truncated nature, so this was not considered for average calculations. DcPIPLC6B was predicted to have the longest protein sequence among all PI-PLC protein sequences in three orchid species. The average molecular weight for PePIPLC, DcPI-PLC, and AsPI-PLC protein sequences was

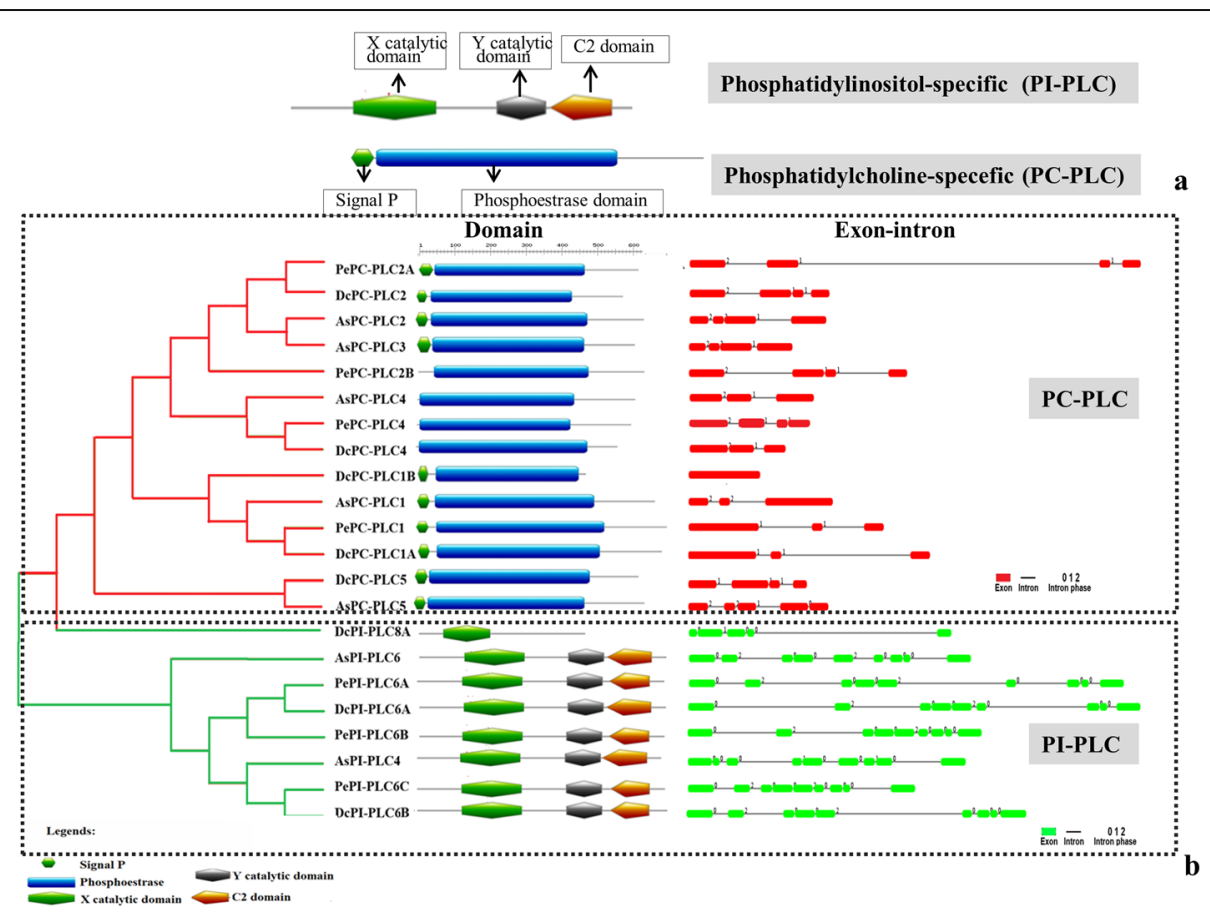

Fig. 1 Domain and gene architecture analysis. a Specific domains of PI-PLC (X catalytic domain, Y catalytic domain, calcium/lipid-binding) and PC-PLC (signal P and phosphoesterase) categories. b Domains and exon-intron architecture for PI-PLC and PC-PLC for P. equestris, D. catenatum, and $A$. shenzhenica 


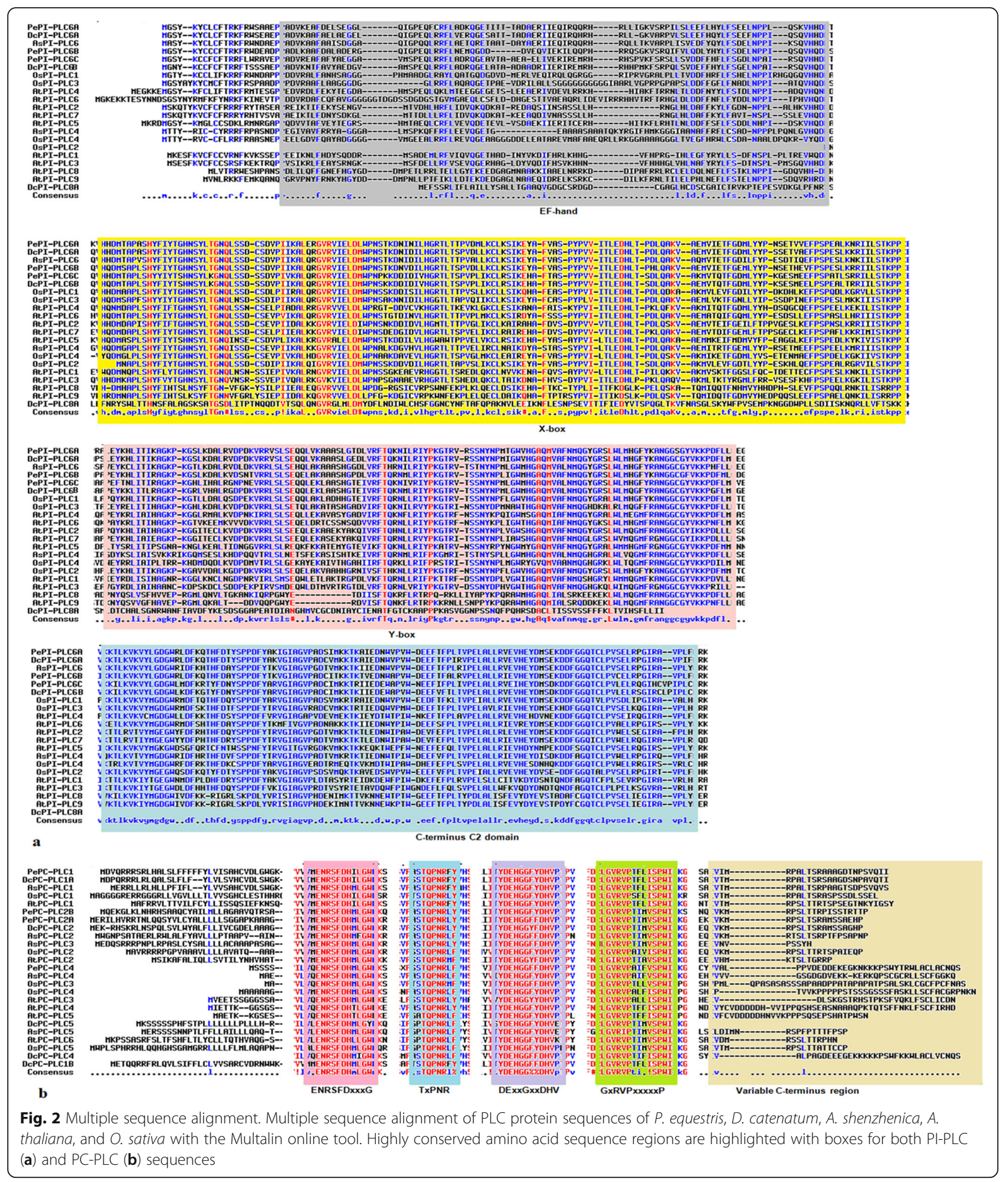

$67.8 \mathrm{kDa}, 68.1 \mathrm{kDa}$, and $67.25 \mathrm{kDa}$ respectively. The isoelectric point for all the PI-PLC ranged from 5.04 to 6.46 with an average aliphatic index of 77 (Table 2). In the case of PC-PLC protein sequences, the average length for PePC-PLC, DcPC-PLC, and AsPC-PLC was 531aa, 481aa, and 524aa respectively. The molecular weight analysis showed that the average molecular weight of PePC-PLC, DcPC-PLC, and AsPC-PLC 


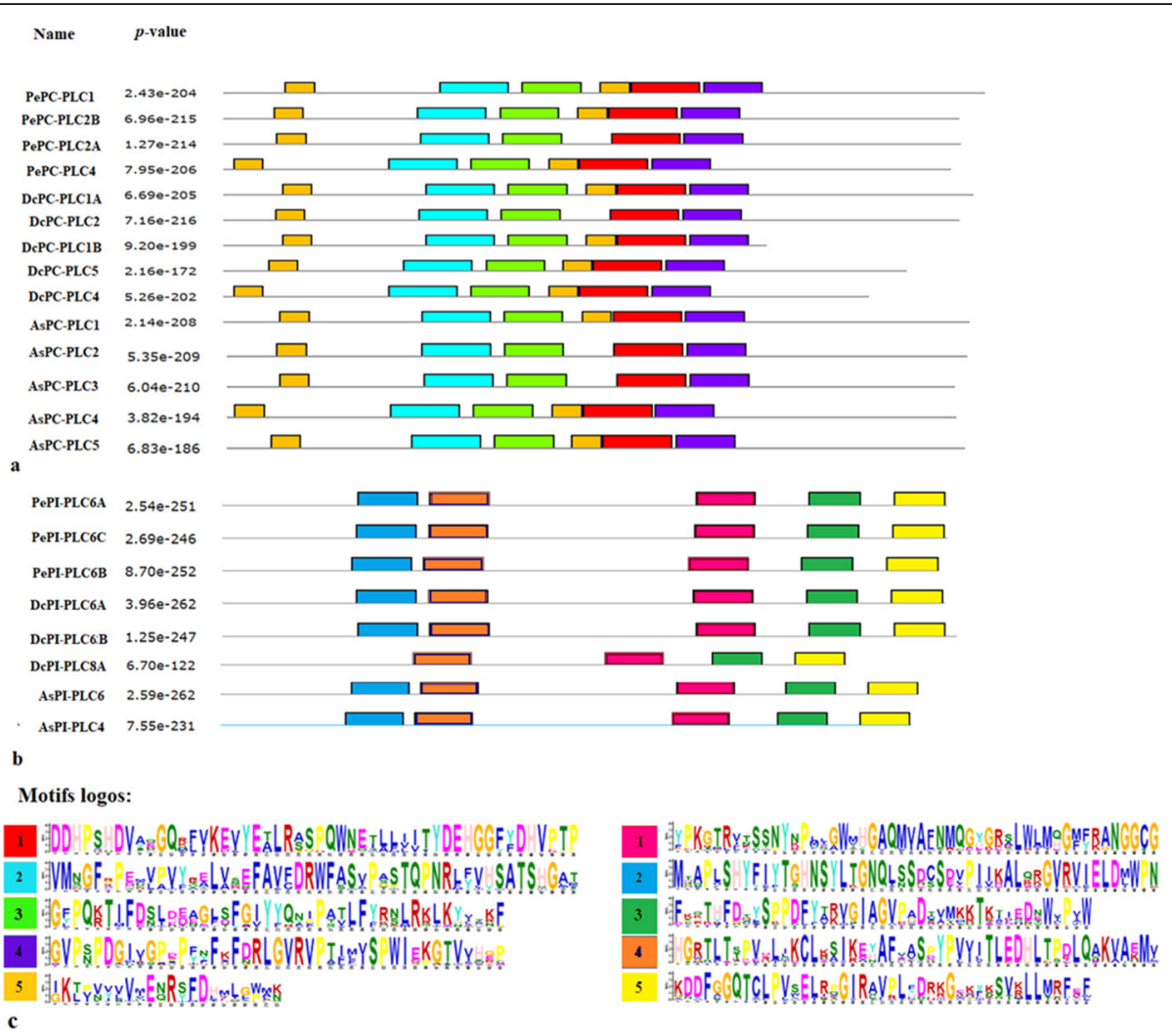

Fig. 3 Motif analyses in PePLC, DcPLC, and AsPLC. Motifs were predicted by the MEME suite online server. a Conserved motifs in PePC-PLC, DCPC-PLC, and AsPC-PLC sequences, marked in colored boxes. b Conserved motifs in PePI-PLC, DCPI-PLC, and AsPI-PLC sequences, marked in colored boxes. c Sequence logo of PI-PLC and PC-PLC protein motifs obtained by the MEME server

proteins was nearly equal to $59.2 \mathrm{kDa}, 53.8 \mathrm{kDa}$, and $58.46 \mathrm{kDa}$, individually. The isoelectric point for all PCPLC protein sequences ranged from 5.27 to 8.54 . The average aliphatic index for protein sequences was 74.18 . In addition to this, all the PLC proteins were observed to have a negative GRAVY value indicating their hydrophilic nature. Subcellular localization studies showed that most of the proteins were localized in the cytoplasm, nucleus, and mitochondria. Ten PC-PLC protein sequences were reported to have signal peptides (PePCPLC1, PePC-PLC2A, DcPC-PLC1A, DcPC-PLC2, DcPCPLC1B, DcPC-PLC5, AsPC-PLC1, AsPC-PLC2, AsPCPLC3, and AsPC-PLC5). The transmembrane region prediction indicated the presence of a transmembrane region in four proteins (PePC-PLC1, DcPC-PLC1A, and AsPC-PLC2) (Table 2).

\section{Phylogenetic analysis}

Phylogenetic analysis was performed for PLC protein sequences of $P$. equestris, $D$. catenatum, and $A$. shenzhenica by clustering along with protein sequences of $O$. sativa and $A$. thaliana to understand the evolutionary relatedness of this gene family to both dicots and monocots. All the proteins clustered along with their counterparts in the PI-PLC and PC-PLC subgroups (Fig. 4).

\section{Genomic locus, gene structure, and gene duplication events}

Genomic scaffold and stretch were identified for candidate genes and enlisted (Table 3). The exon-intron architecture analysis of $P$. equestris, D. catenatum, and $A$. shenzhenica showed the presence of nine exons and eight introns among all PePI-PLC, DcPI$P L C$, and AsPI-PLC members. All PI-PLC genes of the three orchids were dominated by phase 0 introns indicating less disruption of the codon (Fig. 1), while in the case of PC-PLC, seven genes were predicted to have four exons and three introns, four genes with three exons and two introns, and one was with five exons and four introns. $D C P C-P L C 1 B$ was intron-less (Fig. 1, Table 3). The genes of this PC-PLC subgroup were dominated by phase 2 introns, which indicates the disruption of the codon between the second and third bases. These studies also indicated that the maximum number of exons was 
Table 2 Physiocochemical characterization of PePLC, DcPLC, and AsPLC proteins

\begin{tabular}{|c|c|c|c|c|c|c|c|c|c|c|}
\hline Protein & NCBI ID & $\mathbf{L}(\mathbf{a a})$ & MW & pI & Ins & AI & GV & LOC & SP & $\mathbf{T M}$ \\
\hline \multicolumn{11}{|c|}{ Phalaenopsis equestris } \\
\hline PePI-PLC6A & XP 020578795.1 & 596 & 67886.2 & 5.5 & 48.06 & 80.13 & -0.523 & Cytoplasmic & NO & 0 \\
\hline PePI-PLC6C & XP 020579604.1 & 597 & 68399 & 6.46 & 54.7 & 76.73 & -0.475 & Nuclear & NO & 0 \\
\hline PePI-PLC6B & XP 020578229.1 & 590 & 67391.7 & 5.76 & 51.26 & 79 & -0.52 & Cytoplasmic & $\mathrm{NO}$ & 0 \\
\hline PePC-PLC1 & XP_020581391.1 & 548 & 60891 & 7.35 & 45.21 & 75.47 & -0.33 & Mitochondrial & YES & 1 \\
\hline PePC-PLC2B & XP 020583114.1 & 528 & 59053.1 & 8.54 & 50.49 & 72.58 & -0.419 & Mitochondrial & NO & 0 \\
\hline PePC-PLC2A & XP 020585574.1 & 529 & 58884.7 & 6.44 & 49.26 & 72.46 & -0.388 & Nuclear & YES & 0 \\
\hline PePC-PLC4 & XP_020596989.1 & 522 & 58366.1 & 5.79 & 41.17 & 71.49 & -0.427 & Cytoplasmic & $\mathrm{NO}$ & 0 \\
\hline \multicolumn{11}{|c|}{ Dendrobium catenatum } \\
\hline DcPI-PLC6A & XP 020672047.1 & 594 & 67618.7 & 5.48 & 49 & 78.11 & -0.539 & Cytoplasmic & $\mathrm{NO}$ & 0 \\
\hline DePI-PLC6B & XP_020690772.1 & 604 & 68607 & 6.07 & 50.39 & 72.96 & -0.54 & Nuclear & $\mathrm{NO}$ & 0 \\
\hline DePI-PLC8A & XP 020688457.1 & 401 & 43466.9 & 5.04 & 41.9 & 74.46 & -0.146 & Extracellular & YES & 1 \\
\hline DcPC-PLC1A & XP 020695228.1 & 538 & 60208.1 & 6.88 & 48.98 & 77.23 & -0.361 & Mitochondrial & YES & 1 \\
\hline DcPC-PLC1B & XP 020683218.1 & 390 & 44252.1 & 6.01 & 41.67 & 74.26 & -0.276 & $\begin{array}{c}\text { Plasma } \\
\text { membrane }\end{array}$ & YES & 0 \\
\hline DcPC-PLC2 & XP 020688675.1 & 528 & 58849.3 & 6.07 & 43.77 & 69.81 & -0.415 & Nuclear & YES & 0 \\
\hline DcPC-PLC5 & XP 020680107.1 & 490 & 54252.4 & 5.69 & 43.41 & 81.59 & -0.178 & Extracellular & YES & 0 \\
\hline DcPC-PLC4 & XP 020673618.1 & 463 & 51654.2 & 5.27 & 43.24 & 72.18 & -0.383 & Cytoplasmic & $\mathrm{NO}$ & 0 \\
\hline \multicolumn{11}{|c|}{ Apostasia shenzhenica } \\
\hline AsPI-PLC6 & PKA62680.1 & 595 & 67938.3 & 6.13 & 45.78 & 78.32 & -0.547 & Cytoplasmic & $\mathrm{NO}$ & 0 \\
\hline AsPI-PLC4 & PKA66915.1 & 588 & 66684.8 & 6.18 & 44.42 & 76.12 & -0.433 & Cytoplasmic & $\mathrm{NO}$ & 0 \\
\hline AsPC-PLC1 & PKA55093.1 & 535 & 60020.9 & 7.08 & 46.14 & 76.58 & -0.355 & Mitochondrial & YES & 0 \\
\hline AsPC-PLC2 & PKA53711.1 & 527 & 59081 & 6.44 & 45.49 & 71.46 & -0.368 & Mitochondrial & YES & 1 \\
\hline AsPC-PLC3 & PKA67015.1 & 518 & 57703.1 & 5.7 & 49.87 & 74.58 & -0.377 & Cytoplasmic & YES & 0 \\
\hline AsPC-PLC4 & PKA53122.1 & 519 & 57336.7 & 5.44 & 43.22 & 71.52 & -0.363 & Cytoplasmic & $\mathrm{NO}$ & 0 \\
\hline AsPC-PLC5 & PKA65307.1 & 525 & 58197.66 & 5.54 & 53.15 & 77.41 & -0.256 & Cytoplasmic & YES & 0 \\
\hline
\end{tabular}

Isoelectric point (pl), protein molecular weight (MW) in kDa, instability index (Ins), aliphatic index (Al) grand average of hydropathy (GV), localization (LOC), signal peptide (SP) transmembrane domain (TM)

asymmetrical in nature because they were flanked by more than one intronic phase (Fig. 1). There were no duplication events predicted in any of the plants (Table S1).

\section{Promoter analysis and spatio-temporal expression analysis}

The PLC gene sequences were analyzed up to $1500 \mathrm{bp}$ upstream from the gene start site. The result showed the presence of conserved cis-regulatory elements within $P$. equestris, D. catenatum, and A. shenzhenica promoter region and this disclosed the significance of $P L C$ genes in growth and developmental processes and stress responses (Fig. 5; Table S2). Detailed plant-wise analysis of promoter sequences of Phospholipase $C$ genes revealed the presence of various cis-regulatory elements along with core promoter elements TATAbox (TATABOX5) and CAAT-box (CAATBOX1). The analysis showed the correlation function with the concerned genes were root-specific (ROOTMOTIFTAPOX1), mesophyll-specific (CACTFTPPCA1), pollenspecific (POLLEN1LELAT52), wound-activating W-box (WBOXNTERF3), WRKY proteins binding to W-box (WRKY71OS), dehydration-responsive (MYC), ABRElike binding site motif (ABRE) involved in abscisic acid regulations, auxin-responsive elements (AuxREs), salicylic acid- and ethylene-mediating response elements (ASF1, ERELEE4) and cold-, drought-, and ABAresponsive elements (LTRE) with consensus core sequences ATATT, YACT, AGAAA, TGACY, CANNTG, ACGTG, TGACGTGGC/KGTCCCAT, TGACG, AWTTCAAA, and CCGAC. The presence of these 


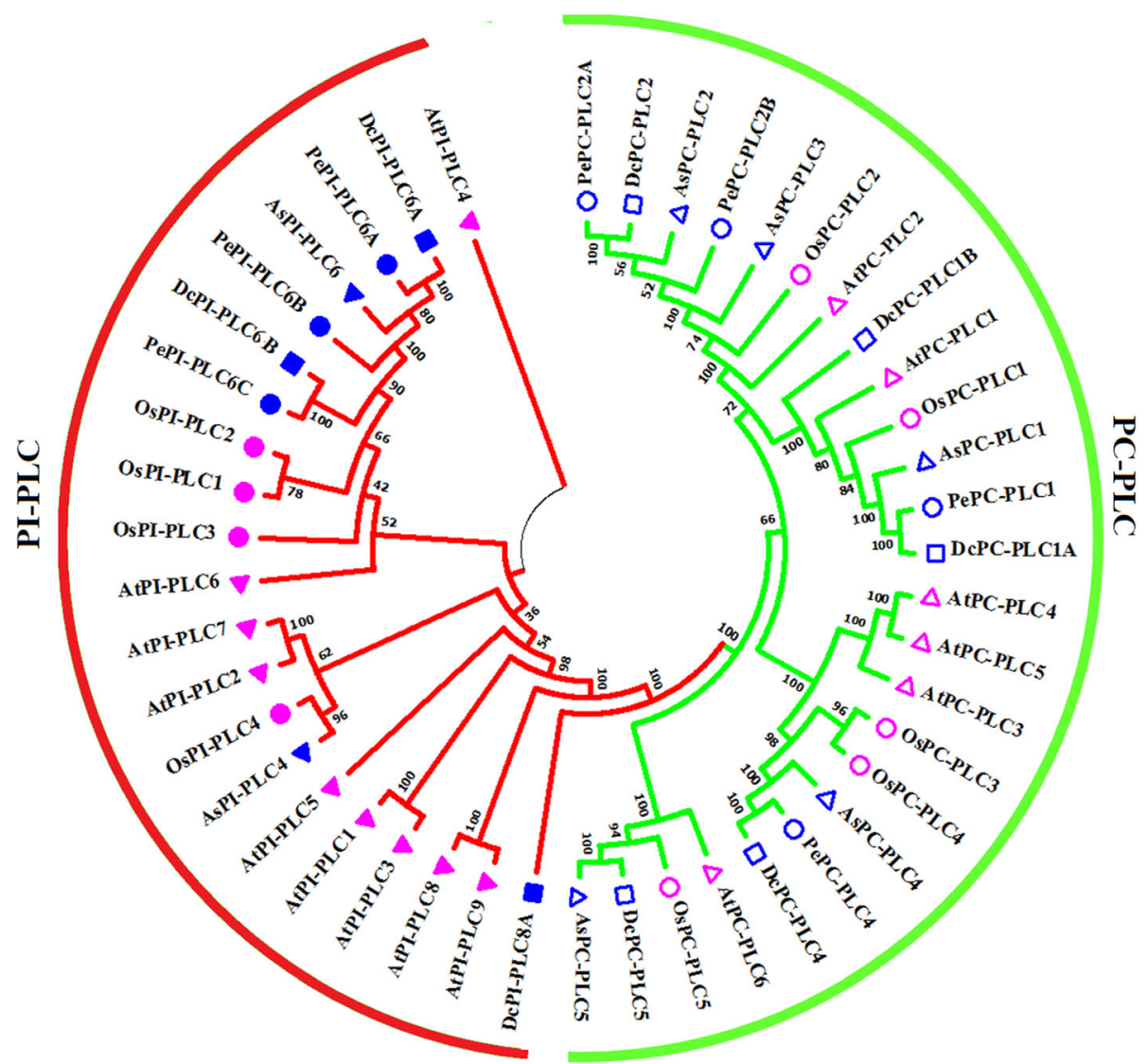

Fig. 4 Phylogenetic analysis of PePLC, DCPLC and AsPLC proteins. Phylogenetic clustering of PePLC, DcPLC, and AsPLC protein sequences was done with AtPLC, and OsPLC sequences. The PI-PLC and PC-PLC groups are marked respectively in red and green

elements accounts for the responsive nature of $P L C$ genes under biotic and abiotic stresses and in various developmental processes (Table S2). The expression profile for PePLC and DcPLC was constructed on the basis of the RPKM value in various developmental stages like leaf, stem, root, sepal, petal, pollen, and gynostemium. Similarly, for AsPLC genes profile was constructed for tissues like tuber, pollen, and seeds. The analysis indicates that the PePC-PLC1, DcPC$P L C 1 A$, and $A s P C-P L C 1$ genes had significant expression in all the tissues under study. DcPC-PLC1A, DcPC$P L C 2$, PePC-PLC2A, and AsPC-PLC2 were showing outstanding expression in pollens, while $D c P C-P L C 2$ and $P e P C-P L C 2 A$ also have high expression in gynostemium. AsPC-PLC4 had predominant expression in seeds, whereas expression in seeds is not studied in $P$. equestris and D. catenatum. The PePI-PLC6A, DcPI$P L C 6 A$, and AsPI-PLC6 were showing significant expression in vegetative tissues like leaf, root, stem, and tubers. The PePI-PLC6A and DCPI-PLC6A also had high expression in gynostemium, floral bud, and lip (Fig. 6).

\section{Molecular modeling}

Homology modeling is a technique, which provides new insights into protein structure and understanding the mechanism of protein function. A total of six proteins PePI-PLC6A, DcPI-PLC6A, AsPI-PLC6, PePC-PLC1, DcPC-PLC1A, and AsPC-PLC1 were taken for the comparative protein structure study from $P$. equestris, $D$. catenatum, and $A$. shenzhenica on the basis of their expression profile. The secondary structures were analyzed using the SOPMA server, which indicates that all the predicted PI-PLC and PC-PLC proteins were dominated by random coils ranging from 44.37 to $46.30 \%$ and 51.59 to $56.02 \%$, respectively (Fig. 7). The random coils are often described as regions, where the folded chain acts more flexibly and dynamically than other secondary conformational structures. The secondary structure analysis indicated the proportion of alpha-helix, extended strand, beta-turn, and random coils in protein was almost the same in PePI-PLC and PePC-PLC proteins and their orthologs in D. catenatum and A. shenzhenica. The proteins taken from the PI-PLC group of $P$. equestris, $D$. catenatum, and A. shenzhenica were dominated by beta- 
Table 3 Gene characterization table of PePLC, DcPLC, and AsPLC genes

\begin{tabular}{|c|c|c|c|c|}
\hline Gene & Gene Scaffold & Gene Stretch & No. of Exon & No. of Intron \\
\hline \multicolumn{5}{|c|}{ Phalaenopsis equestris } \\
\hline PePI-PLC6A & Scaffold 000226 & c872018-834743 & 9 & 8 \\
\hline PePI-PLC6C & Scaffold 000250 & $1234727-1246476$ & 9 & 8 \\
\hline PePI-PLC6B & Scaffold 000223 & c1513360-1493208 & 9 & 8 \\
\hline PePC-PLC1 & Scaffold000002 & $29108649-29125803$ & 3 & 2 \\
\hline PePC-PLC2B & Scaffold 000373 & c67948-46469 & 4 & 3 \\
\hline PePC-PLC $2 A$ & Scaffold000499 & c377026-317380 & 4 & 3 \\
\hline PePC-PLC4 & Scaffold211064 & $60299-65983$ & 4 & 3 \\
\hline \multicolumn{5}{|c|}{ Dendrobium catenatum } \\
\hline DcPI-PLC6A & original_scaffold_212897 & $7314-46930$ & 9 & 8 \\
\hline DcPI-PLC6B & fragScaff_scaffold_1608 & c4527995-4509548 & 9 & 8 \\
\hline DcPI-PLC8A & fragScaff_scaffold_697 & $114922-138982$ & 5 & 4 \\
\hline DcPC-PLC1A & fragScaff_scaffold_1056 & $4382553-4407053$ & 3 & 2 \\
\hline$D c P C-P L C 1 B$ & original_scaffold_129785 & c2593-1421 & 1 & 0 \\
\hline DcPC-PLC2 & fragScaff_scaffold_716 & $16873819-16882457$ & 4 & 3 \\
\hline DcPC-PLC5 & fragScaff_scaffold_574 & $793408-799457$ & 4 & 3 \\
\hline DcPC-PLC4 & fragScaff_scaffold_963 & c270153-266580 & 3 & 2 \\
\hline \multicolumn{5}{|c|}{ Apostasia shenzhenica } \\
\hline AsPI-PLC6 & fragScaff_scaffold_33 & $2155165-2173684$ & 9 & 8 \\
\hline AsPI-PLC4 & fragScaff_scaffold_2 & c6844989-6863157 & 9 & 8 \\
\hline AsPC-PLC1 & fragScaff_scaffold_97 & c2071539-2080701 & 3 & 2 \\
\hline AsPC-PLC2 & fragScaff_scaffold_110 & c3198428-3206567 & 4 & 3 \\
\hline$A s P C-P L C 3$ & fragScaff_scaffold_0 & c967371-970326 & 4 & 3 \\
\hline AsPC-PLC4 & fragScaff_scaffold_117 & c820528-826850 & 3 & 2 \\
\hline AsPC-PLC5 & fragScaff_scaffold_12 & c1061342-1070102 & 5 & 4 \\
\hline
\end{tabular}

sheets, each of them having 15 beta-sheets and 12 alphahelix structures. The little variation at the EF-domain region in the sequence of AsPI-PLC6 and at N-terminal region in DcPI-PLC6A was observed. The members of the PC-PLC group were observed with six beta-sheet in their tertiary structure. But DcPC-PLC1A was predicted to have a large number of variations in their protein sequence at the alpha-helix region (Fig. 8). The superimposition of 3D-structure of PePI-PLC6A, DcPI-PLC6A, AsPI-PLC6, and PePC-PLC1, DcPC-PLC1A, and AsPCPLC1 indicate their almost similar nature with little variation as indicated by the root mean square deviation (RMSD) value, which measures the average distance between the atoms of superimposed proteins (Table 4). RMSD values of the PI-PLC sub-group indicate that the variation in the structure of beta-sheets among PePIPLC6A, DcPI-PLC6A, and AsPI-PLC6 protein sequences is comparatively less than alpha helices and random coils. However, in PC-PLC proteins, variations in the beta-sheets were observed to be more in comparison to the alpha-helix, except in PePC-PLC1 and AsPC-PLC1. This analysis showed that PLC proteins are conserved at structural level in $P$. equestris, D. catenatum, and $A$. shenzhenica.

\section{Discussion}

The $P L C$ gene family plays a major role in many critical cellular processes, including signal transduction, vesicular trafficking, cytoskeletal rearrangement, and secretion, which are necessary for plant growth and development, 

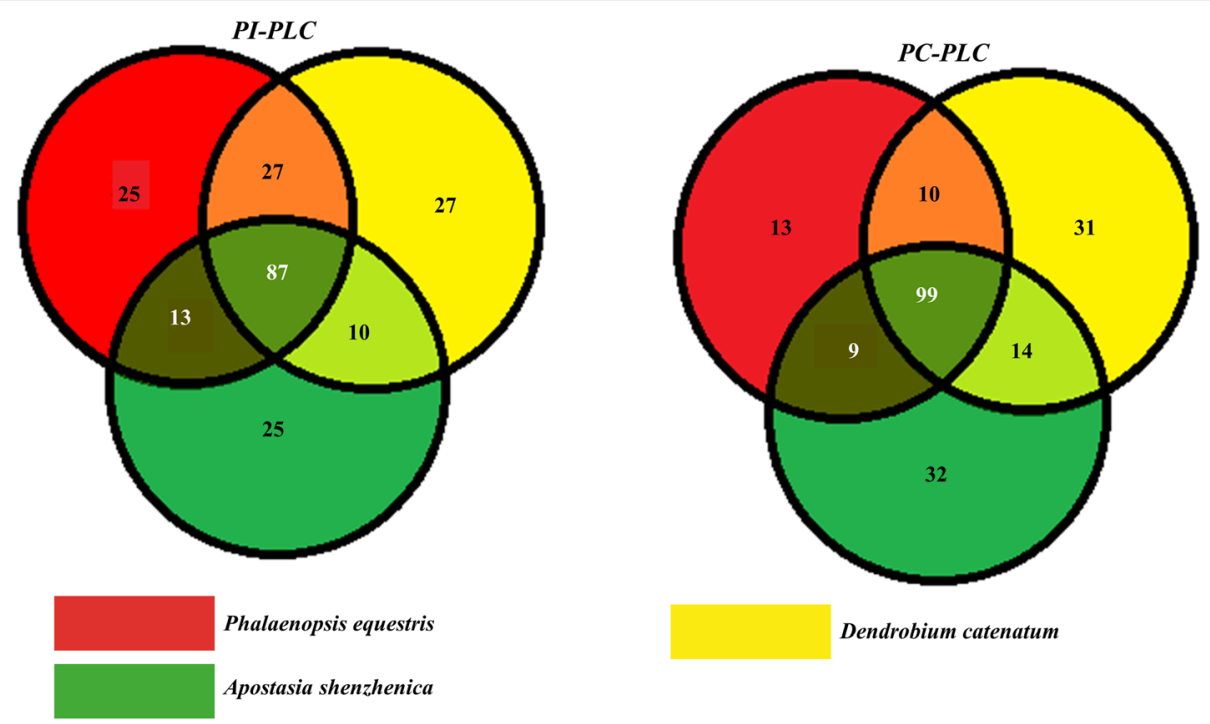

Fig. 5 Promoter analysis: Venn diagram showing common numbers of promoters in PI-PLC (a) and PC-PLC (b)

stress responses, and immune system maintenance [11, 12, 26]. Nevertheless, the reports on PLC transcription factors in orchids are not available till now. In the present study, $P L C$ genes were identified from $P$. equestris [36], D. catenatum [37], and A. shenzhenica [38]. In our study of genome-wide exploration of $P$. equestris, $D$. catenatum, and $A$. shenzhenica through various bioinformatics techniques revealed the presence of seven, eight, and seven PLC encoding genes. The pattern of distribution of the number of genes among both sub-classes in the PLC family in orchids is somewhat similar to the rice
[12]. However, there is a variation in the number of PLC genes in Arabidopsis (15), rice (9), and soybean (12) [5, 10, 12] (Table 5) and this difference in the size of the $P L C$ gene family in monocots and dicots must be due to the loss of genes during the course of evolution. The whole PLC gene family is divided into two groups, PIPLC and PC-PLC, on the basis of domain analysis, phylogenetic clustering, and homology modeling in accordance with reports on Arabidopsis, rice, tomato, cotton, and Brassica napus [9, 10, 12, 14, 19]. Like in Arabidopsis and rice, the PI-PLCs also have

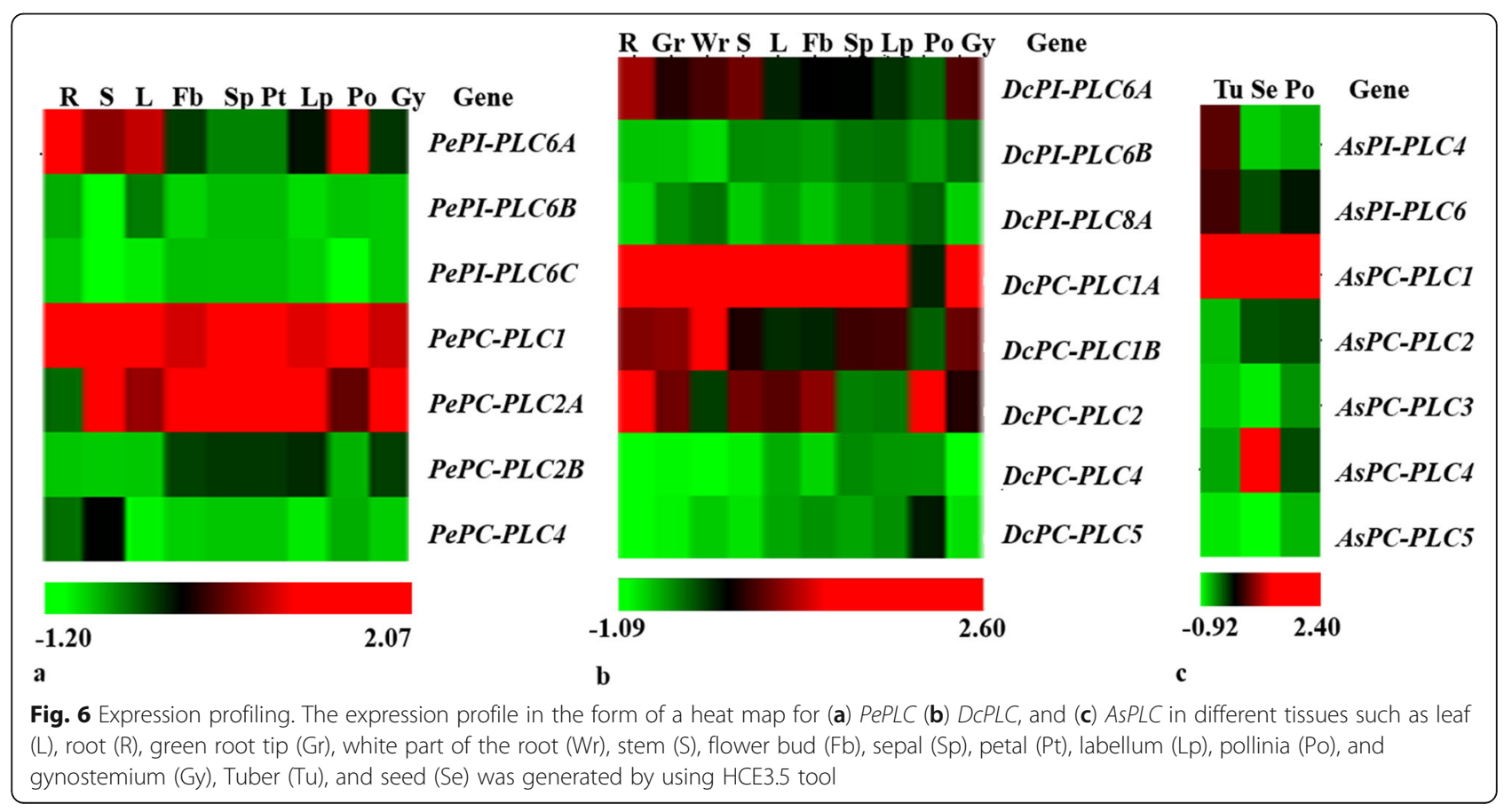


a

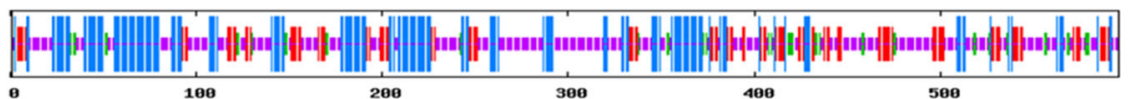

b

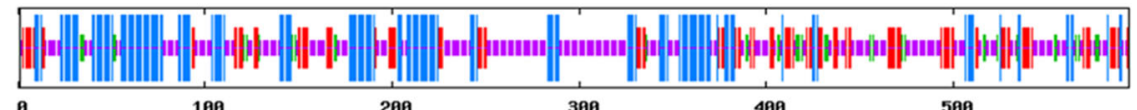

c

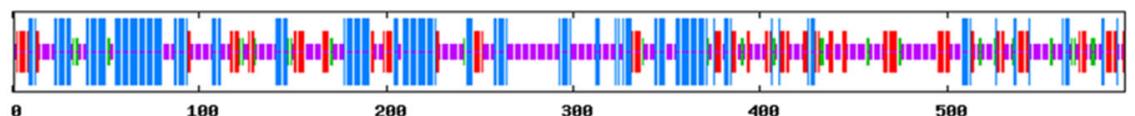

d

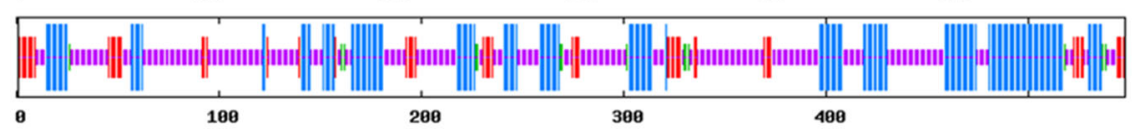

e

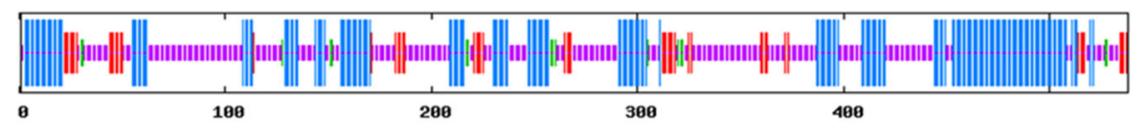

f

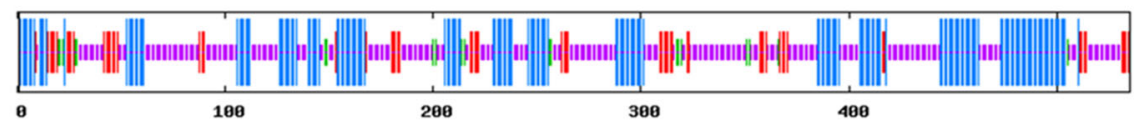

A

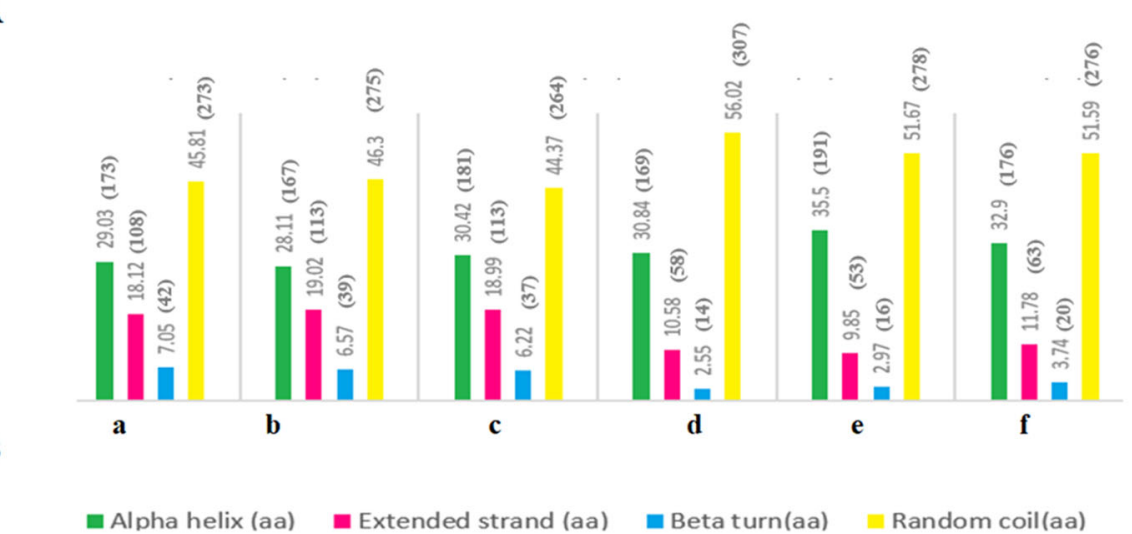

Fig. 7 Structural analysis of proteins. A Diagrammatical representation of Secondary structures (a: PePI-PLC6A; b: DcPI-PLC6A; c: AsPI-PLC6; d: PePC-PLC1; e: DCPC-PLC1A; f: AsPC-PLC1). B Bar graph showing the percentage of alpha-helix, beta-sheet, and random coil of (a, b, c, d, e, f)

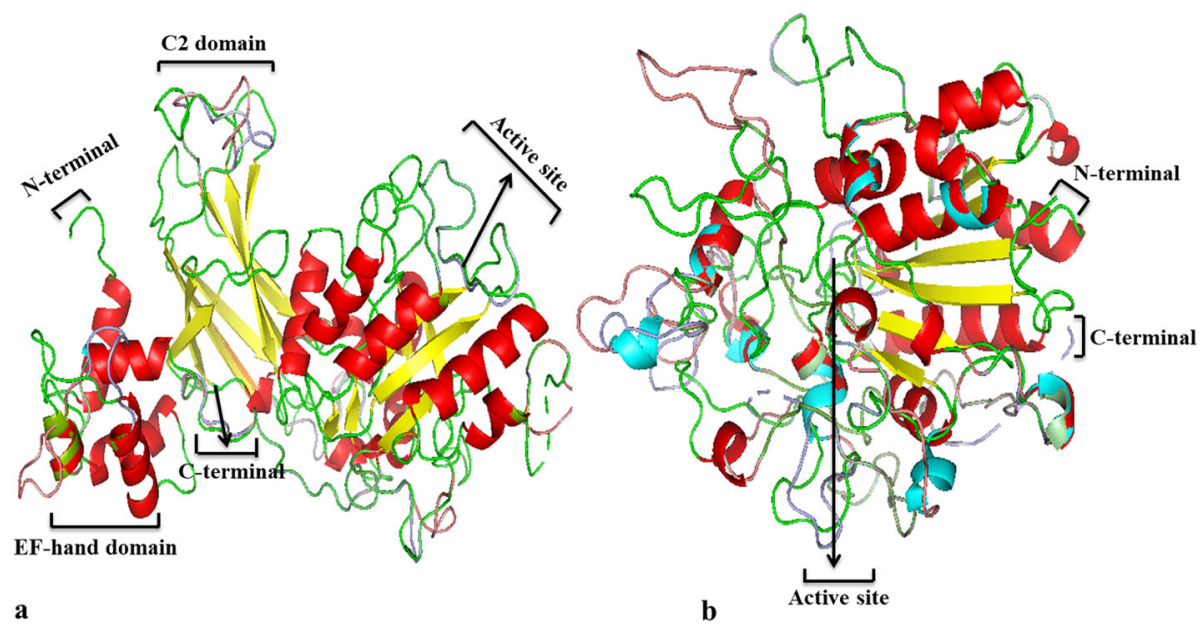

Fig. 8 Simulated three-dimensional super-imposed structures. a Superimposed structure of PePI-PLC6A, DcPI-PLC6A and AsPI-PLC6. b Superimposed structure of PePC-PLC1, DCPC-PLC1A and AsPC-PLC1 
Table 4 Root mean square deviation (RMSD) value of superimposed PI-PLC and PC-PLC proteins

\begin{tabular}{|l|l|l|l|l|l|}
\hline \multirow{2}{*}{$\begin{array}{l}\text { Reference } \\
\text { Protein }\end{array}$} & $\begin{array}{l}\text { Target } \\
\text { Protein }\end{array}$ & Whole protein & Beta sheet & Alpha helix & Random coil \\
\hline PePI-PLC6A & AsPI-PLC6 & 1.628520 over 504 residues & 0.788913 over 88 residues & 1.445982 over 136 residues & 2.315726 over 280 residues \\
\hline PePI-PLC6A & DePI-PLC6A & 2.024540 over 504 residues & 0.000001 over 88 residues & 0.000002 over 128 residues & 3.056325 over 256 residues \\
\hline DcPI-PLC6A & AsPI-PLC6 & 1.540918 over 512 residues & 0.788913 over 88 residues & 1.554225 over 128 residues & 2.509973 over 256 residues \\
\hline & & & & & \\
\hline PePC-PLC1 & AsPC-PLC1 & 1.492541 over 376 residues & 0.000004 over 24 residues & 3.169870 over 96 residues & 2.728313 over 200 residues \\
\hline PePC-PLC1 & DcPC-PLC1A & 2.799216 over 360 residues & 4.770873 over 24 residues & 4.291452 over 72 residues & 3.484524 over 192 residues \\
\hline DcPC-PLC1A & AsPC-PLC1 & 3.227150 over 296 residues & 4.770872 over 24 residues & 3.208077 over 64 residues & 3.435517 over 168 residues \\
\hline
\end{tabular}

characteristic PI-PLC-X and Y catalytic domains and phospholipid-binding $\mathrm{C} 2$ domain at the $\mathrm{C}$-terminal (Fig. 1 ). The conserved EF-hand region is observed in multiple sequence alignment of PI-PLC sequence of orchids, like rice and Arabidopsis [10, 12]. The identified PCPLC proteins are predicted with a signature phosphoesterase domain, which consists of four conserved regions ENRSFDxxxG, TxPNR, DExxGxxDHV, GxRVPxxxxxP, and variable $\mathrm{C}$-terminus region (Figs. 1 and 2). The physicochemical analysis of PI-PLC proteins of P. equestris, $D$. catenatum, and $A$. shenzhenica showed that the average length and weight of the PI-PLC proteins are in range with the PI-PLC proteins of rice [12]. Likewise, the average length and average weight of PC-PLC proteins fall within the range of those in Arabidopsis [10]. The signal peptides were predicted in 11 orchid PLC protein sequences, which is confirmatory with the presence of signal peptides in four proteins in Gossypium hirsutum, three in G. arboretum, and four in G. raimondii [9]. Furthermore, the evolutionary analysis of PePLC, DcPLC, and AsPLC along with PLC sequences of A. thaliana and O. sativa showed the clustering of PIPLC and PC-PLC proteins in dedicated groups with high bootstrap values. The clustering of proteins with their closest relative indicated their conserved nature at the sequence level. The structural analysis for PLC genes and proteins showed the conserved nature of this gene family at the structural level as well. The exon-intron architecture revealed that all the PI-PLC members contain 7-9 exons. A similar kind of exon-intron pattern remains conserved among rice, Gossypium sp., Brassica napus, and Arabidopsis. However, in the case of PCPLC, a number of exons ranged from 1 to 5, five genes had three exons, seven had four, one had five exons, and one had only one exon, which is also reported in PCPLC members of rice, Gossypium sp., and Brassica napus $[9,12,19]$. Duplication event analysis indicated that the PLC genes of $P$. equestris, $D$. catenatum and $A$.

Table 5 Size of the Phospholipase C (PLC) gene family in some dicot and monocot species

\begin{tabular}{|l|c|c|c|c|}
\hline \multirow{2}{*}{ Name of Plant } & \multicolumn{3}{c|}{ Number of Genes } & \multirow{2}{*}{ Reference } \\
\cline { 2 - 4 } & PI-PLC & PC-PLC & Total PLC & \\
\hline Gossypium hirsutum & 12 & 9 & 21 & {$[9]$} \\
\hline Glycine max & 15 & 9 & 20 & {$[15,73]$} \\
\hline Gossypium arboretum & 9 & 6 & 15 & {$[9]$} \\
\hline Gossypium raimondii & 9 & 6 & 15 & {$[9]$} \\
\hline Arabidopsis thaliana & 9 & 6 & 15 & {$[10,11]$} \\
\hline Cicer arietinum & 6 & 3 & 9 & {$[70]$} \\
\hline & & & & {$[72]$} \\
\hline Triticum aestivum & 11 & 15 & 26 & {$[23]$} \\
\hline Zea mays & 5 & 6 & 11 & {$[12]$} \\
\hline Oryza sativa & 4 & 5 & 9 & {$[71]$} \\
\hline Brachypodium distachyon & 4 & 4 & 8 & {$[$ present work] } \\
\hline Dendrobium catenatum & 3 & 5 & 8 & {$[p r e s e n t$ work] } \\
\hline Phalaenopsis equestris & 2 & 5 & 7 & {$[$ present work] } \\
\hline Apostasia shenzhenica & 2 & 5 & 7 & \\
\hline
\end{tabular}

\begin{tabular}{|c|c|}
\hline & Dicots \\
\hline & Monocots \\
\hline
\end{tabular}


shenzhenica did not participate in any significant duplication event. Similar, studies have been reported from rice where no duplication events were reported [12].

The promoter analysis of the PLC gene family in orchids indicates the presence of core promoter elements along with various other elements such as root-specific, mesophyll-specific, pollen-specific, stress-responsive, hormone-responsive elements and pathogen-responsive elements. These promoter elements are in line with functions performed by PLC genes. The dominance of abiotic stress (LTRE, PRE, MYC), hormone (ASF1, ERE), and pathogen (W-BOX, WRKY) responsive elements reflects the role of the $P L C$ gene family in immunity responses and in both abiotic and biotic stress resistance. Similarly, the presence of cis-elements has been reported in the rice promoter with a predicted role in regulating gene expression patterns during abiotic stress conditions [12]. The presence of auxin-responsive cis-elements in the promoter region of the PLC gene family has also been observed in cotton [9]. Additionally, the presence of ASF-1and LTRE promoter elements, which are involved in the activation of various genes by auxin/salicylic acid-and ABA-mediated pathways and indicates the role of $P L C$ genes in cold, drought, and salt stress responses [12, 65]. Similarly, the role of PLC genes (OSPI-PLC1, OsPI-PLC3, and OsPI$P L C 4)$ is also reported in rice during cold, drought, and salt stress responses $[12,66]$. The presence of W-box (TGAC) cis-elements in the promoter regions of AsPLC, $D C P L C$, and PePLC indicates the responsiveness of this family toward biotic stresses. The W-box has the capacity to bind with the WRKY transcription factor, which has a role in pathogen response [67] (Table S2). Expression analysis of PLCs indicated that these genes have differential expression in different tissues indicating their specific role in various physiological processes and developmental processes. In Arabidopsis, NPC5 (PC-PLC5) expression is reported from the floral organ and the PI-PLC2 gene is reported to have a role in reproductive development [68, 69], and in conformity, AsPC-PLC5 showed moderate expression in pollen. The PePI-PLC6A and DCPI-PLC6A genes displayed significant expression in reproductive tissues (floral bud, pollen, lip, and gynostemium) in tune with the expression of their orthologs (BnaPI-PLC6A3, BnaPI-PLC6A5, BnaPI-PLC6C3, and BnaPI-PLC6C4) in Brassica napus [19]. In rice, OsNPC4 showed higher expression in seed developmental stages while OsPLC3 was downregulated in seed stages [12]. A similar interesting expression profile was observed in AsPC-PLC4 and AsPC$P L C 3$ as well (Fig. 6). The three-dimensional structure analysis in Arabidopsis indicates that the backbone of the tertiary structure of PC-PLC is made up of beta-sheets (which includes 7 beta structures) [6]; a similar trend is also observed in orchid PC-PLC proteins, which are composed of six beta-sheet structures surrounded by around
16 alpha-helix structures. The PI-PLC proteins of orchids are dominated by 15 beta-sheets and nearly 17 alpha-helix structures (Figs. 7 and 8).

\section{Conclusions}

In this study, we have successfully done genome-wide characterization of the $P L C$ gene family in three orchid species $P$. equestris, $D$. catenatum and $A$. shenzhenica through various in silico approaches. Total of $22 P L C$ genes were predicted in three orchid species, which were conserved at sequence and structure level. The expression profiles and cis-regulatory of all the $P L C$ genes of three orchids were analyzed during various development stages. Both the expression analysis and promoter analysis indicate that the PLC gene family is involved in various developmental processes and stress responses. The study suggests that PLC is important for plant development and adaptation to various biotic and abiotic stresses.

\begin{abstract}
Abbreviations
PLA: Phospholipase A; PLD: Phospholipase C; PLC: Phospholipase C; PIPLC: phosphatidylinositol-specific phospholipase C; PC-

PLC: Phosphatidylcholine-specific; pl: Isoelectric point; GRAVY: Grand average of Hydropathicity; MEGA: Molecular evolutionary genetics analysis; MEME: Multiple EM for Motif Elicitation; JTT: Jones-Taylor-Thornton; DAG: Diacylglycerol; PA: Phosphatidic acid; DGPP: Diacylglycerol pyrophosphate; IP6: Inositol hexakisphosphate; CDS: Coding sequences
\end{abstract}

\section{Supplementary Information}

The online version contains supplementary material available at https://doi. org/10.1186/s43141-021-00217-z.

\section{Additional file 1: Table S1. \\ Additional file 2: Table S2.}

\section{Acknowledgements}

The authors are grateful to the Department of Botany, Panjab University, Chandigarh, for infrastructure support.

\section{Authors' contributions}

JKS conceptualized the work. MK, TRR, and $\mathrm{H}$ executed the experiments and prepared the original draft. JKS reviewed and edited the manuscript. All authors have read and approved the final version.

\section{Funding}

The authors are thankful to the Department of Science and Technology (DST), for the INSPIRE fellowship under the INSPIRE program for Junior Research Fellowship (DST/INSPIRE fellowship/2017/IF170940) and the Department of Science and Technology (DST), Government of India, for partial financial support under the Promotion of University Research and Scientific Excellence (PURSE) grant scheme.

\section{Availability of data and materials}

Supplementary data associated with this article are available in the online version.

\section{Declarations}

Ethics approval and consent to participate NA 


\section{Consent for publication}

NA

\section{Competing interests}

The authors declared that they have no competing interests.

\section{Author details}

'Department of Botany, Panjab University, Chandigarh 160014, India. ${ }^{2}$ Department of Microbiology and Cell Sciences, University of Florida, Gainesville, FL 32611, USA.

\section{Received: 4 March 2021 Accepted: 26 July 2021}

\section{Published online: 21 August 2021}

\section{References}

1. Hong Y, Zhao J, Guo L, Kim SC, Deng X, Wang G, Zhang G, Li M, Wang $X$ (2016) Plant phospholipases $D$ and $C$ and their diverse functions in stress responses. Prog Lipid Res 62:55-74 https://doi.org/1 0.1016/j.plipres.2016.01.002

2. Chap H (2016) Forty-five years with membrane phospholipids, phospholipases and lipid mediators: A historical perspective. Biochimie 125: 234-249 https://doi.org/10.1016/j.biochi.2016.04.002

3. Wang X (2001) Plant phospholipases. Annu Rev Plant Biol 52(1):211-231 https://doi.org/10.1146/annurev.arplant.52.1.211

4. Exton JH (1994) Messenger molecules derived from membrane lipids. Curr Opin Cell Biol 6(2):226-229. https://doi.org/10.1016/0955-0674(94)90140-6

5. Shi J, Gonzales RA, Bhattacharyya MK (1995) Characterization of a plasma membrane-associated phosphoinositide-specific phospholipase C from soybean. Plant J 8(3):381-390. https://doi.org/10.1046/j.1365-313X.1 995.08030381.x

6. Pokotylo I, Pejchar P, Potocky M, Kocourkova D, Krckova Z, Ruelland E, Kravets V, Martinec J (2013) The plant non-specific phospholipase C gene family. Novel competitors in lipid signalling. Prog Lipid Res 52(1):62-79 https://doi.org/10.1016/j.plipres.2012.09.001

7. Pokotylo I, Kolesnikov Y, Kravets V, Zachowski A, Ruelland E (2014) Plant phosphoinositide-dependent phospholipases C: variations around a canonical theme. Biochimie 96:144-157 https://doi.org/10.1016/j.biochi.2013. 07.004

8. Nakamura Y, Ngo AH (2020) Non-specific phospholipase C (NPC): an emerging class of phospholipase C in plant growth and development. J Plant Res 133(4):489-497 https://doi.org/10.1007/s10265-020-01199-8

9. Zhang B, Wang Y, Liu JY (2018) Genome-wide identification and characterization of phospholipase C gene family in cotton (Gossypium spp.) Sci China Life Sci 61(1):88-99 https://doi.org/10.1007/s11427-017-9053-y

10. Tasma IM, Brendel V, Whitham SA, Bhattacharyya MK (2008) Expression and evolution of the phosphoinositide-specific phospholipase $C$ gene family in Arabidopsis thaliana. Plant Physiol Biochem 46(7):627-637 https://doi.org/1 0.1016/j.plaphy.2008.04.015

11. Zheng SZ, Liu Y, Li B, Shang ZL, Zhou RG, Sun DY (2012) Phosphoinositidespecific phospholipase C9 is involved in the thermotolerance of Arabidopsis. Plant J 69(4):689-700 https://doi.org/10.1111/j.1365-313X.2011. 04823.x

12. Singh A, Kanwar P, Pandey A, Tyagi AK, Sopory SK, Kapoor S, Pandey GK (2013) Comprehensive genomic analysis and expression profiling of phospholipase C gene family during abiotic stresses and development in rice. PLoS One 8(4) https://dx.doi.org/10.1371\%2Fjournal.pone.0062494

13. Komis G, Galatis B, Quader H, Galanopoulou D, Apostolakos P (2008) Phospholipase $C$ signaling involvement in macrotubule assembly and activation of the mechanism regulating protoplast volume in plasmolyzed root cells of Triticum turgidum. New Phytol 178: 267-282. https://doi.org/1 0.1111/j.1469-8137.2007.02363.x, 2

14. Vossen JH, Abd-El-Haliem A, Fradin EF, van den Berg GC, Ekengren SK, Meijer HJ, Seifi A, Bai Y, Have AT, Munnik T, Thomma BPHJ, Joosten MHAJ (2010) Identification of tomato phosphatidylinositol-specific phospholipaseC (PI-PLC) family members and the role of PLC4 and PLC6 in HR and disease resistance. Plant J 62(2):224-239. https://doi.org/10.1111/j.1365-313 X.2010.04136.x

15. Chou WM, Shigaki T, Dammann C, Liu YQ, Bhattacharyya MK (2004) Inhibition of phosphoinositide-specific phospholipase $C$ results in the induction of pathogenesis-related genes in soybean. Plant Biol 6(6):664-672. https://onlinelibrary.wiley.com/doi/pdf/10.1055/s-2004-830351
16. Kopka J, Pical C, Gray JE, Müller-Röber B (1998) Molecular and enzymatic characterization of three phosphoinositide-specific phospholipase $C$ isoforms from potato. Plant Physiol 116(1):239-250. https://doi.org/10.1104/ pp.116.1.239

17. Liu HT, Huang WD, Pan QH, Weng FH, Zhan JC, Liu Y, Wan SB, Liu YY (2006) Contributions of PIP2-specific-phospholipase $C$ and free salicylic acid to heat acclimation-induced thermotolerance in pea leaves. J Plant Physiol. https://doi.org/10.1016/j.jplph.2005.04.027 163(4):405-416

18. Georges F, Das S, Ray H, Bock C, Nokhrina K, Kolla VA, Keller W (2009) Overexpression of Brassica napus phosphatidylinositol-phospholipase C2 in canola induces significant changes in gene expression and phytohormone distribution patterns, enhances drought tolerance and promotes early flowering and maturation. Plant Cell Environ 32: 1664-1681 https://doi.org/1 0.1111/j.1365-3040.2009.02027.x, 12

19. labal S, Ali U, Fadlalla T, Li Q, Liu H, Lu S, Guo L (2020) Genome wide characterization of phospholipase A \& C families and pattern of lysolipids and diacylglycerol changes under abiotic stresses in Brassica napus L. Plant Physiol Biochem 147:101-112 https://doi.org/10.1016/j.plaphy.2019.12.017

20. Kim YJ, Kim JE, Lee JH, Lee MH, Jung HW, Bahk YY, Hwang BK, Hwang I, Kim WT (2004) The Vr-PLC3 gene encodes a putative plasma membranelocalized phosphoinositide-specific phospholipase C whose expression is induced by abiotic stress in mung bean (Vigna radiata L.). FEBS Lett 556(13):127-123. https://doi.org/10.1016/S0014-5793(03)01388-7

21. Huang CH, Crain RC (2009) Phosphoinositide-specific phospholipase C in oat roots: association with the actin cytoskeleton. Planta 230(5):925-933. https://doi.org/10.1007/s00425-009-0990-7

22. Pan YY, Wang $X$, Ma LG, Sun DY (2005) Characterization of phosphatidylinositol-specific phospholipase C (PI-PLC) from Lilium daviddi pollen. Plant Cell Physiol 46(10):1657-1665. https://doi.org/10.1 093/pcp/pci181

23. Wang CR, Yang AF, Yue GD, Gao Q, Yin HY, Zhang JR (2008) Enhanced expression of phospholipase C 1 (ZmPLC1) improves drought tolerance in transgenic maize. Planta 227(5):1127-1140. https://doi.org/10.1007/s00425007-0686-9

24. Repp A, Mikami K, Mittmann F, Hartmann E (2004) Phosphoinositide-specific phospholipase $C$ is involved in cytokinin and gravity responses in the moss Physcomitrella patens. Plant J 40(2):250-259. https://doi.org/10.1111/j.13 65-313X.2004.02205.x

25. Mikami K, Repp A, Graebe-Abts E, Hartmann E (2004) Isolation of cDNAs encoding typical and novel types of phosphoinositide-specific phospholipase C from the moss Physcomitrella patens. J Exp Bot 55(401): 1437-1439. https://doi.org/10.1093/jxb/erh140

26. Abd-El-Haliem AM, Vossen JH, van Zeijl A, Dezhsetan S, Testerink C, Seidl MF, Beck M, Strutt J, Robatzek S, Joosten MHAJ (2016) Biochemical characterization of the tomato phosphatidylinositol-specific phospholipase C (PI-PLC) family and its role in plant immunity. Biochimica et Biophysica Acta (BBA)-Molecular and Cell Biology of Lipids 1861(9):1365-1378 https:// doi.org/10.1016/j.bbalip.2016.01.017

27. Hunt L, Mills LN, Pical C, Leckie CP, Aitken FL, Kopka J, Mueller-Roeber B, McAnish MR, Hetheringtone AM, Gray JE (2003) Phospholipase C is required for the control of stomatal aperture by ABA. Plant J 34(1):47-55 https://doi. org/10.1046/j.1365-313X.2003.01698.x

28. Nakamura Y, Awai K, Masuda T, Yoshioka Y, Takamiya Kl, Ohta H (2005) A novel phosphatidylcholine-hydrolyzing phospholipase $C$ induced by phosphate starvation in Arabidopsis. J Biol Chem 280(9): 7469-7476.https:// doi:10.1074/jbc.M408799200

29. Zhang J, Xia K, Yang Y, Yang H (2015) Overexpression of Arabidopsis phosphoinositide-specific phospholipase C5 induces leaf senescence. Plant Cell, Tissue and Organ Culture (PCTOC) 120(2):585-595 https://doi.org/10.1 007/s11240-014-0625-y

30. Gao K, Liu YL, Li B, Zhou RG, Sun DY, Zheng SZ (2014) Arabidopsis thaliana phosphoinositide-specific phospholipase C isoform 3 (AtPLC3) and AtPLC9 have an additive effect on thermotolerance. Plant Cell Physiol 55(11):18731883. https://doi.org/10.1093/pcp/pcu116

31. Ren H, Gao K, Liu Y, Sun D, Zheng S (2017) The role of AtPLC3 and AtPLC9 in thermotolerance in Arabidopsis. Plant Signal Behav 12(10):e1162368 https://doi.org/10.3389/fpls.2017.01164

32. D'Ambrosio JM, Couto D, Fabro G, Scuffi D, Lamattina L, Munnik T, Andersson MX, Alvarez ME, Zipfel C, Laxalt AM (2017) Phospholipase C2 Affects MAMP-triggered immunity by modulating ROS production. Plant Physiol 175(2):970-981 https://doi.org/10.1104/pp.17.00173 
33. Qu H, Guan Y, Wang Y, Zhang S (2017) PLC-mediated signaling pathway in pollen tubes regulates the gametophytic self-incompatibility of Pyrus species. Front Plant Sci 8:1164 https://doi.org/10.3389/fpls.2017.01164

34. Kocourkova D, Krckova Z, Pejchar P, Veselkova S, Valentova O, Wimalasekera R, Scherer GF, Martinec J (2011) The phosphatidylcholine-hydrolysing phospholipase C NPC4 plays a role in response of Arabidopsis roots to salt stress. J Exp Bot 62(11):3753-3763 https://doi.org/10.1093/jxb/err039

35. Janda M, Planchais S, Djafi N, Martinec J, Burketova L, Valentova O, Zachowski A, Ruelland E (2013) Phosphoglycerolipids are master players in plant hormone signal transduction. Plant Cell Rep 32(6):839-851 https://doi. org/10.1105/tpc.108.062992

36. Cai J, Liu X, Vanneste K, Proost S, Tsai WC, Liu KW, Chen LJ, He Y, Xu Q, Bian C, Zheng Z, Sun F, Liu W, Hsiao YY, Pan ZJ, Hsu CC, Yang YP, Hsu YC, Chuang YC, Dievart A, Dufayard JF, Xu X, Wang JY, Wang J, Xiao XJ, Zhao XM, du R, Zhang GQ, Wang M, Su YY, Xie GC, Liu GH, Li LQ, Huang LQ, Luo YB, Chen HH, van de Peer Y, Liu ZJ (2015) The genome sequence of the orchid Phalaenopsis equestris. Nat Genet 47(1):65-72.https://doi.org/10.1038/ ng.3149. https://doi.org/10.1038/ng.3149

37. Zhang GQ, Xu Q, Bian C, Tsai WC, Yeh CM, Liu KW, Yoshida K, Zhang LS, Chang SB, Chen F, Shi Y et al (2016) The Dendrobium catenatum Lindl. genome sequence provides insights into polysaccharide synthase, floral development and adaptive evolution. Sci Rep 6(1):1 https://doi.org/10.1038/ srep 19029

38. Zhang GQ, Liu KW, Li Z, Lohaus R, Hsiao YY, Niu SC, Wang JY, Lin YC, Xu Q, Chen LJ, Yoshida K, Fujiwara S, Wang ZW, Zhang YQ, Mitsuda N, Wang M, Liu GH, Pecoraro L, Huang HX, Xiao XJ, Lin M, Wu XY, Wu WL, Chen YY, Chang SB, Sakamoto S, Ohme-Takagi M, Yagi M, Zeng SJ, Shen CY, Yeh CM, Luo YB, Tsai WC, van de Peer Y, Liu ZJ (2017) The Apostasia genome and the evolution of orchids. Nature 549(7672):379-383. https://doi.org/10.1038/ nature23897. https://doi.org/10.1038/nature23897

39. Lam Y, Ng TB, Yao RM, Shi J, Xu K, Sze SC, Zhang KY (2015) Evaluation of chemical constituents and important mechanism of pharmacological biology in Dendrobium plants. Evid Based Complement Alternat Med 2015. https://doi.org/10.1155/2015/841752, 2015, 1, 25

40. Givnish TJ, Spalink D, Ames M, Lyon SP, Hunter SJ, Zuluaga A, Lles WJD, Clements MA, Arroyo MTK, Leebens-Mack J, Endara L, Kriebel R, Neubig MK, Whitten WM, Williams NH (1814) Cameron KM (2015) Orchid phylogenomics and multiple drivers of their extraordinary diversification. Proc R Soc B Biol Sci 282(1814):20151553. https://doi.org/10.1098/rspb.201 5.1553

41. Altschul SF, Wootton JC, Gertz EM, Agarwala R, Morgulis A, Schäffer AA, Yu YK (2005) Protein database searches using compositionally adjusted substitution matrices. FEBS J 272(20):5101-5109 https://doi.org/10.1111/j.1 742-4658.2005.04945.x

42. Schultz J, Copley RR, Doerks T, Ponting CP, Bork P (2000) SMART: a webbased tool for the study of genetically mobile domains. Nucleic Acids Res 28(1):231-234 https://doi.org/10.1093/nar/28.1.231

43. Sigrist CJ, De Castro E, Cerutti L, Cuche BA, Hulo N, Bridge A, Bougueleret L, Xenarios I (2012) New and continuing developments at PROSITE. Nucleic Acids Res 41(D1):D344-D347.https://doi.org/10.1093/nar/gks1067. https:// doi.org/10.1093/nar/gks1067

44. Corpet F (1998) Multiple sequence alignment with hierarchical clustering. Nucleic Acids Res 16(22):10881-10890 https://doi.org/10.1093/ nar/16.22.10881

45. Bailey TL, Boden M, Buske FA, Frith M, Grant CE, Clementi L, Ren J, Li WW, Noble WS (2009) MEME SUITE: tools for motif discovery and searching. Nucleic Acids Res 37(suppl_2): W202-8. https://doi.org/10.1093/nar/gkp335

46. Gasteiger E, Hoogland C, Gattiker A, Duvaud S, Wilkins MR, Appel RD, Bairoch A (2005) Protein identification and analysis tools on the ExPASy server. Springer:571-607 https://doi.org/10.1385/1-59259-890-0:571

47. Yu CS, Chen YC, Lu CH, Hwang JK (2006) Prediction of protein subcellular localization. Proteins: Structure, Function, and Bioinformatics 64(3):643-651. https://doi.org/10.1002/prot.21018. https://doi.org/10.1002/prot.21018

48. Horton P, Park KJ, Obayashi T, Fujita N, Harada H, Adams-Collier CJ, Nakai K (2007) WoLF PSORT: protein localization predictor. Nucleic Acids Res 35(suppl_2): W585-7. https://doi.org/10.1093/nar/gkm259

49. Petersen TN, Brunak S, Von Heijne G, Nielsen H (2011) SignalP 4.0: discriminating signal peptides from transmembrane regions. Nat Methods 8(10):785. https://doi.org/10.1038/nmeth.1701-786

50. Krogh A, Larsson B, Von Heijne G, Sonnhammer EL (2001) Predicting transmembrane protein topology with a hidden Markov model: application to complete genomes. J Mol Biol 305(3):567-580 https://doi.org/10.1006/ jmbi.2000.4315

51. Kumar S, Stecher G, Li M, Knyaz C, Tamura K (2019) MEGAX: evolutionary genetics analysis across computing platforms. Mol Biol Evol 35(6):15471549. https://doi.org/10.1093/molbev/msy096

52. Luo H, Gao F, Lin Y (2015) Evolutionary conservation analysis between the essential and nonessential genes in bacterial genomes. Sci Rep 5(1):1-8 https://doi.org/10.1038/srep13210

53. Xu L, Dong Z, Fang L, Luo Y, Wei Z, Guo H, Wang Y (2019) OrthoVenn2: a web server for whole-genome comparison and annotation of orthologous clusters across multiple species. Nucleic Acids Res 47(W1):W52-W58 https:// doi.org/10.1093/nar/gkz333

54. Hu B, Jin J, Guo AY, Zhang H, Luo J, Gao G (2015) GSDS 2.0: an upgraded gene features visualization server. Bioinformatics 31(8):1296-1297. https://doi.org/1 0.1093/bioinformatics/btu817. https://doi.org/10.1093/bioinformatics/btu817

55. Higo K, Ugawa Y, Iwamoto M, Korenaga T (1999) Plant cis-acting regulatory DNA elements (PLACE) database: 1999. Nucleic Acids Res 27(1):297-300 https://doi.org/10.1093/nar/27.1.297

56. Pirooznia M, Nagarajan V, Deng Y (2007) GeneVenn-A web application for comparing gene lists using Venn diagrams. Bioinformation 1(10):420-422. https://doi.org/10.6026/97320630001420

57. Edgar RC (2004) MUSCLE: multiple sequence alignment with high accuracy and high throughput. Nucleic Acids Res 32(5):1792-1797 https://doi.org/1 0.1093/nar/gkh340

58. Pearson WR (2013) An introduction to sequence similarity ("homology") searching. Curr Protoc Bioinformatics 42:3-1. https://doi.org/10.1002/04712 50953.bi0301s42, 1.

59. Kodama Y, Shumway M, Leinonen R (2012) The Sequence Read Archive: explosive growth of sequencing data. Nucleic Acids Res 40(D1):D54-D56 https://doi.org/10.1093/nar/gkr854

60. Wagner GP, Kin K, Lynch VJ (2012) Measurement of mRNA abundance using RNA-seq data: RPKM measure is inconsistent among samples. Theory Biosci 131(4):281-285 https://doi.org/10.1007/s12064-012-0162-3

61. Seo J, Gordish-Dressman H, Hoffman EP (2006) An interactive power analysis tool for microarray hypothesis testing and generation. Bioinformatics 22(7):808-814. https://doi.org/10.1093/bioinformatics/btk052. https://doi.org/10.1093/bioinformatics/btk052

62. Sapay N, Guermeur Y, Deléage G (2006) Prediction of amphipathic in-plane membrane anchors in monotopic proteins using a SVM classifier. BMC bioinformatics 7(1):255. https://dx.doi.org/10.1186\%2F1471-2105-7-255. https://doi.org/10.1186/1471-2105-7-255

63. Kelley LA, Mezulis S, Yates CM, Wass MN, Sternberg MJ (2015) The Phyre2 web portal for protein modeling, prediction and analysis. Nat Protoc 10(6): 845. https://doi.org/10.1038/nprot.2015.053-858

64. DeLano WL (2002) Pymol: An open-source molecular graphics tool. CCP4 Newsletter on protein crystallography 40(1):82-92

65. Chen W, Singh KB (1999) The auxin, hydrogen peroxide and salicylic acid induced expression of the Arabidopsis GST6 promoter is mediated in part by an ocs element. Plant J 19(6):667-677 https://doi.org/10.1046/j.1365-313 x.1999.00560.x

66. Singh A, Bhatnagar N, Pandey A, Pandey GK (2015) Plant phospholipase C family: Regulation and functional role in lipid signaling. 58(2): 139-146. https://doi.org/10.1016/j.ceca.2015.04.003

67. Eulgem T, Rushton PJ, Schmelzer E, Hahlbrock K, Somssich IE (1999) Early nuclear events in plant defence signalling: rapid gene activation by WRKY transcription factors. EMBO J 18(17):4689-4699 https://doi.org/10.1093/ emboj/18.17.4689

68. Gaude N, Nakamura Y, Scheible WR, Ohta H, Dörmann P (2008) Phospholipase C5 (NPC5) is involved in galactolipid accumulation during phosphate limitation in leaves of Arabidopsis. Plant J 56(1):28-39 https://doi. org/10.1111/j.1365-313X.2008.03582.x

69. Li L, He Y, Wang Y, Zhao S, Chen X, Ye T, Wu Y, Wu Y (2015) Arabidopsis PLC 2 is involved in auxin-modulated reproductive development. Plant $J$ 84(3):504-515 https://doi.org/10.1111/tpj.13016

70. Sagar S, Biswas DK, Singh A (2020) Genomic and expression analysis indicate the involvement of phospholipase $\mathrm{C}$ family in abiotic stress signaling in chickpea (Cicer arietinum). Gene 753:144797 https://doi.org/10.1 016/i.gene.2020.144797

71. Wang X, Liu Y, Li Z, Gao X, Dong J, Yang M (2020) Expression and evolution of the phospholipase $\mathrm{C}$ gene family in Brachypodium distachyon. Genes \& Genomics 42(9):1041-1053 https://doi.org/10.1007/s13258-020-00973-1 
72. Wang X, Liu Y, Li Z, Gao X, Dong J, Zhang J, Zhang L, Thomashow LS, Weller DM, Yang M (2020) Genome-wide identification and expression profile analysis of the phospholipase $\mathrm{C}$ gene family in wheat (Triticum aestivum L.). Plants (Basel) 9(7): 885. doi: https://doi.org/10.3390/pla nts9070885.

73. Chen ZF, Ru JN, Sun GZ, Du Y, Chen J, Zhou YB, Zhang XH (2021) Genomicwide analysis of the PLC family and detection of GmPI-PLC7 responses to drought and salt stresses in soybean. Front Plant Sci 12. https://doi.org/1 $0.3389 /$ fpls.2021.631470

\section{Publisher's Note}

Springer Nature remains neutral with regard to jurisdictional claims in published maps and institutional affiliations.

Submit your manuscript to a SpringerOpen ${ }^{\mathcal{O}}$ journal and benefit from:

- Convenient online submission

Rigorous peer review

- Open access: articles freely available online

High visibility within the field

- Retaining the copyright to your article

Submit your next manuscript at $\boldsymbol{\sim}$ springeropen.com 